\title{
Cystatin C Triggers Neuronal Degeneration in a Model of Multiple System Atrophy
}

\author{
Yasuyo Suzuki, Chenghua Jin, and Ikuru Yazawa
}

From the Laboratory of Research Resources, Research Institute for Longevity Sciences, National Center for Geriatrics and Gerontology, Aichi, Japan

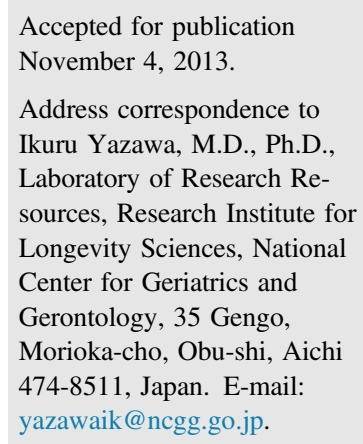

\begin{abstract}
Multiple system atrophy is an intractable neurodegenerative disease caused by $\alpha$-synuclein ( $\alpha$-syn) accumulation in oligodendrocytes and neurons. With the use of a transgenic mouse model overexpressing human $\alpha$-syn in oligodendrocytes, we demonstrated that oligodendrocytic $\alpha$-syn inclusions induce neuronal $\alpha$-syn accumulation, resulting in progressive neuronal degeneration. The mechanism through which oligodendrocytic $\alpha$-syn inclusions trigger neuronal $\alpha$-syn accumulation leading to multiple system atrophy is unknown. In this study, we identified cystatin C, an oligodendrocyte-derived secretory protein that triggers $\alpha$-syn up-regulation and insoluble $\alpha$-syn accumulation, in neurons of the mouse central nervous system. Cystatin $C$ was released by mouse oligodendrocytes overexpressing human $\alpha$-syn, and extracellular cystatin $C$ increased the expression of the endogenous $\alpha$-syn gene in wild-type mouse neurons. These neurons then accumulate insoluble $\alpha$-syn and may undergo apoptosis. Cystatin $\mathrm{C}$ is a potential pathogenic signal triggering neurodegeneration in multiple system atrophy. (Am J Pathol 2014, 184: 790-799; http://dx.doi.org/10.1016/j.ajpath.2013.11.018)
\end{abstract}

Oligodendrocytes surround and ensheath neuronal axons to support action potential propagation. Oligodendrocytes and neurons also communicate by releasing chemical signals that allow functional coupling of axonal activity and oligodendroglial function. Moreover, signals released from dysfunctional oligodendrocytes may contribute to neuronal degeneration. ${ }^{1}$ Multiple system atrophy (MSA) is a neurodegenerative disease caused by $\alpha$-synuclein ( $\alpha$-syn) accumulation in oligodendrocytes and neurons and is clinically characterized by various combinations of parkinsonism, cerebellar dysfunction, and autonomic nervous system failure. $^{2-4}$ No effective therapy is available for MSA-associated neurodegeneration.

Two pathological hallmarks of MSA are glial cytoplasmic inclusions (GCIs) and neuronal inclusions, both of which are composed of $\alpha$-syn. The GCIs are confined to oligodendrocytes and are the first neuropathological manifestations of MSA, preceding the neuronal inclusions that ultimately lead to neurodegeneration and neurological deficits. ${ }^{5-10}$ Mouse models of MSA have revealed that $\alpha$-syn accumulation in oligodendrocytes contributes to progressive neuronal degeneration in the central nervous system $(\mathrm{CNS}) .^{11-13} \mathrm{We}$ previously demonstrated that transgenic $(\mathrm{Tg})$ mice expressing human $\alpha$-syn in oligodendrocytes under the control of the $2^{\prime}, 3^{\prime}$-cyclic nucleotide $3^{\prime}$-phosphodiesterase (CNP) promoter exhibited motor impairments, progressive brain atrophy, and GCI-like $\alpha$-syn inclusions similar to those described in patients with MSA. ${ }^{13}$ These $\mathrm{Tg}$ mice not only recapitulated many features of MSA neuropathology but also provided evidence that formation of oligodendrocytic $\alpha$-syn inclusions results in neuronal accumulation of insoluble $\alpha$-syn, leading to neuronal dysfunction and degeneration in the mouse CNS. ${ }^{13,14}$ This insoluble $\alpha$-syn accumulates in the CNS by binding to the neuron-specific microtubule protein $\beta$-III tubulin. ${ }^{15,16}$ Although the binding of neuronal $\alpha$-syn to $\beta$-III tubulin is a key process that leads to neuronal degeneration in the MSA mouse model, it is still unclear how oligodendrocytic $\alpha$-syn inclusions trigger neuronal degeneration.

In a subsequent study, we found that the conditioned media (CM) from $\mathrm{Tg}$ mouse brain cultures induced insoluble $\alpha$-syn accumulation in cultured neurons from non-Tg mice. ${ }^{15}$ It has been proposed that an oligodendrocyte-derived signal may trigger the accumulation of insoluble $\alpha$-syn in neurons,

Supported by JSPS KAKENHI grants 25430058 and 25830045

Disclosures: None declared. 
resulting in the progressive neurodegeneration characteristic of MSA. Here, we identified cystatin C as an oligodendrocytic signal that causes neuronal degeneration. Oligodendrocytes overexpressing $\alpha$-syn released cystatin C. Treatment of non$\mathrm{Tg}$ mouse neural cultures with cystatin $\mathrm{C}$ up-regulated $\alpha$ syn expression and led to the accumulation of insoluble $\alpha$-syn in neurons, strongly suggesting that cystatin $\mathrm{C}$ is an oligodendrocytic signal that mediates neurodegeneration in MSA.

\section{Materials and Methods}

\section{Tg Mice and Primary Culture}

Tg mice were generated to express human wild-type $\alpha$-syn in oligodendrocytes under the control of the murine CNP promoter. ${ }^{13}$ Primary cultures of neurons and glial cells were prepared as previously described ${ }^{15}$ with minor modifications. Briefly, cerebral cortices were dissected from P0 to P1 non$\mathrm{Tg}$ and $\mathrm{Tg}$ mice of either sex and dissociated. The cells were plated on $15-\mathrm{mm}$ glass coverslips coated with polyethylenimine $(0.01 \%$; Sigma-Aldrich, St. Louis, MO) at a density of $0.6 \times 10^{5}$ cells $/ \mathrm{cm}^{2}$ for immunocytochemistry or on polyethylenimine-coated $75-\mathrm{cm}^{2}$ flasks at $2.0 \times 10^{5}$ cells/ $\mathrm{cm}^{2}$ for preparation of $\mathrm{CM}$ and biochemical experiments. Cells were maintained in a mixture of Dulbecco's modified Eagle's medium (Wako, Osaka, Japan) plus B27/neurobasal medium (1:1) supplemented with 5\% fetal bovine serum, penicillin $(50 \mathrm{U} / \mathrm{mL})$, streptomycin $(50 \mu \mathrm{g} / \mathrm{mL})$, glutamine $(1$ $\mathrm{mmol} / \mathrm{L})$, and insulin $(50 \mu \mathrm{g} / \mathrm{mL}$; Sigma-Aldrich). Neuronal and glial composition of the neural cultures at 36 days in vitro (DIV) was confirmed by immunocytochemistry; in non-Tg mouse cell cultures, $10.4 \% \pm 4.2 \%$ of all cells were Tuj1positive neurons, $23.5 \% \pm 7.6 \%$ were O4-positive oligodendrocytes, $42.0 \% \pm 6.5 \%$ were glial fibrillary acidic protein-positive astrocytes, and $4.3 \% \pm 2.0 \%$ were Ibalpositive microglia; in $\mathrm{Tg}$ mouse cell cultures, $10.3 \% \pm$ $6.3 \%$ of all cells were Tuj1 positive, $23.4 \% \pm 5.3 \%$ were $\mathrm{O} 4$ positive, $44.0 \% \pm 8.1 \%$ were glial fibrillary acidic protein positive, and $4.7 \% \pm 0.9 \%$ were Iba1 positive. To assay the effect of cystatin $\mathrm{C}$ on neurons, primary cultured cells were treated with purified cystatin C ( 0.1 to $2 \mu \mathrm{g} / \mathrm{mL})$ for 28 days from DIV8. To obtain a nearly pure culture of neurons, after 2 days in neural cultures, the cells were exposed to $1-\beta-D-$ arabinofuranosylcytosine (AraC; $10 \mu \mathrm{mol} / \mathrm{L}$; Sigma-Aldrich) for 3 days. AraC treatment resulted in a dramatic decrease in the number of glial cells in the cultures. All chemicals for culture were purchased from Life Technologies (Carlsbad, CA) unless otherwise stated. All experiments with mice were approved by the National Center for Geriatrics and Gerontology Animal Care and Use Committee.

\section{Oligodendrocyte Culture}

Oligodendrocyte cultures were obtained by a modified procedure of McCarthy and de Vellis. ${ }^{17}$ Briefly, mixed glial cells were grown for 9 to 11 days. To remove microglial cells, primary cultures were shaken rotationally for 1 hour at $160 \mathrm{rpm}$ at $37^{\circ} \mathrm{C}$. The medium was discarded, and fresh medium was added. Cultures were shaken for 20 hours at $220 \mathrm{rpm}$ at $37^{\circ} \mathrm{C}$ in which oligodendrocytes were dislodged from the underlying astrocyte layer. Cells were harvested by centrifugation, resuspended in growth medium, and grown for 14 days on poly-L-lysine-coated glass coverslips. Oligodendrocyte cultures did not contain neuronal cells, and astrocytic contamination was $<10 \%$.

\section{Isolation of Signaling Molecules}

Half of the media from each primary culture derived from $\mathrm{Tg}$ and non-Tg mouse brain was collected twice weekly from DIV7 to DIV40 and replaced with new medium. Samples of CM were fractionated and concentrated by sequential ultrafiltration on Vivaspin20 columns (Sartorius, Goettingen, Germany). First, CM (1 L) were filtered through a 100,000-molecular weight cutoff (MWCO) membrane to remove cell debris and high molecular weight proteins. The fraction passed through the 100,000-MWCO membrane was concentrated with a 50,000-MWCO membrane. The concentrated fraction in $1.5 \mathrm{~mL}$ of $\mathrm{CM}$ was supplemented with $20 \mathrm{mmol} / \mathrm{L}$ Tris- $\mathrm{HCl}(\mathrm{pH} 7.5)$ to $10 \mathrm{~mL}$, and the mixture was loaded at $1 \mathrm{~mL} /$ minute onto a MonoQ 46/100 PE column (GE Healthcare, Buckinghamshire, UK) preequilibrated with $20 \mathrm{mmol} / \mathrm{L}$ Tris- $\mathrm{HCl}(\mathrm{pH}$ 7.5). The flowthrough fraction was collected and concentrated by ultrafiltration through a 5000-MWCO membrane. The flowthrough fraction was then loaded onto a HiLoad 16/60 Superdex 200 column (GE Healthcare) pre-equilibrated with $20 \mathrm{mmol} / \mathrm{L}$ Tris- $\mathrm{HCl}(\mathrm{pH} 7.5)$ containing $0.15 \mathrm{~mol} / \mathrm{L} \mathrm{NaCl}$ and eluted with the same buffer at $0.8 \mathrm{~mL} /$ minute. The eluting proteins were monitored by absorbance at $280 \mathrm{~nm}$ and collected in 3-mL fractions. The protein content of fractions was assessed by SDS-PAGE and silver staining.

\section{In-Gel Digestion and Mass Spectrometry}

Each Superdex 200 fraction from CM of Tg and non-Tg cells was separated on $12 \%$ SDS-polyacrylamide gels and visualized with the Silver Stain MS Kit (Wako). Protein bands specific to the $\mathrm{CM}$ from $\mathrm{Tg}$ mice were excised from silver-stained gels and subjected to in-gel trypsin digestion with the use of the Trypsin Profile IGD Kit (Sigma-Aldrich) according to the manufacturer's instructions. The mixture of tryptic peptides was concentrated, desalted on a ZipTipC18 microcolumn (Millipore, Billerica, MA), and subsequently analyzed by an AXIMA-CFR matrix-assisted laser desorption/ionization time of flight (MALDI-TOF) mass spectrometer (Shimadzu-Kratos, Kyoto, Japan) by using $\alpha$-cyano-4-hydroxycinnamic acid as the matrix. The peptide-mass fingerprinting results generated from MALDI-TOF mass spectroscopy (MS) were used to identify the protein by searching the SWISS-PROT database by using the MASCOT peptide-mass fingerprinting search program (Matrix Science, Inc., Boston, 
http://www.matrixscience.com/cgi/search_form.pl?FORM $V E R=2 \& S E A R C H=P M F$, last accessed July 29, 2011).

\section{Real-Time PCR Analysis}

Harvested tissues and cells were immediately soaked in RNAlater stabilization reagent (Qiagen, Hilden, Germany) and frozen. Total RNA was isolated from tissues and cells by using NucleoSpin RNA II (Takara Bio, Shiga, Japan). Purified total RNA $(1 \mu \mathrm{g})$ was converted to cDNA with the use of the High Capacity cDNA Reverse Transcription Kit (Life Technologies). Gene expression levels were quantified with Power SYBR Green PCR Master Mix (Life Technologies). The primer sequences are as follows: $\alpha$-syn $(S N C A)$ forward, 5'-TCGACGACAGTGTGGTGTAAAGG-3', SNCA reverse, 5'-CACCATGCACCACTCCCTCCTTG-3'; Snca forward, 5'-GCCTGTGGATCCTGGCAGTGAGGC-3'; Snca reverse, 5'-CGCCATGGAAGAGCAGCCGGC-3'; cystatin C (Cst3) forward, 5'-GCGTACCACAGCCGCGCCAT- $3^{\prime}$; Cst 3 reverse, $5^{\prime}$-TGGGGCTGGTCATGGAAAGGACAGT-3'; Bcl2-associated protein $\mathrm{X}$ (Bax) forward, 5'-CCGAGCTGATCAGAACCATCA-3'; Bax reverse, 5'-CTCCAGCCACAAAGATGGTCA-3'; caspase-3 (Casp3) forward, 5'-ACAGTGGGACTGATGAGGAGA-3'; Casp3 reverse, 5'-TGCAAAGGGACTGGATGAACC-3'; ubiquitin $\mathrm{C}(\mathrm{Ubc})$ forward, 5'-CACAGCCCTGCCCTCCCACACA- $3^{\prime}$; $U b c$ reverse, $5^{\prime}$-TGGTGTCACTGGGCTCGACCTCC-3'; Gapdh forward, 5'-AGCAAGGACACTGAGCAAGAGA-3'; Gapdh reverse, 5'-TGGTATTCAAGAGAGTAGGGAGGG-3'; mitochondrial ribo- somal protein L4 (Mrpl4) forward, 5'-AGACCAGGGCTGAGGTGAGT-3'; and $\mathrm{Mrpl} 4$ reverse, 5'-GCCATAAGGGAGAACGGATG-3'. Relative RNA levels were normalized to ubiquitin $\mathrm{C}$ expression. ${ }^{18}$ Stable housekeeping genes Gapdh and Mrpl4 were used as internal controls.

\section{Knockdown of Cst3 and Snca by RNA Interference}

For siRNA knockdown of Cst3 or Snca, lentiviral vectorbased siRNA plasmids (piLenti-siRNA-GFP) that contained target sequences were purchased from Applied Biological Materials Inc. (Vancouver, Canada). The target sequences of the siRNAs are as follows: Cst3-1, 5'-GCAGCTCGTGGCTGGAGTGAACTATTTTT-3'; Cst3-2, 5'-TGACTGACTGTCCTTTCCATGACCAGCCC-3'; Snca-1, 5'-ACAGTGGGAGCTGGGAATATAGCTGC- $3^{\prime}$; and Snca-2, $5^{\prime}$ AGGAAGGCTACCAAGACTATGAGCCTGAA- ${ }^{\prime}$. These plasmids were transfected into primary cultured cells with the use of Lipofectamine 2000 (Life Technologies). After 14 days of transfection, cells were harvested for analysis.

\section{Generation of Stable Cell Line and Purification of Secreted Cystatin C}

The complete cDNA sequences of the Cst3 gene was obtained by RT-PCR cloning with the use of total RNA isolated from the brain tissue of a 6-month-old non- $\mathrm{Tg}$ mouse as a template. To fuse a FLAG tag sequence to the $3^{\prime}$ region of the Cst 3 gene, PCR was performed with primers that contained the tag sequence. The PCR products were subcloned into pT7Blue
A

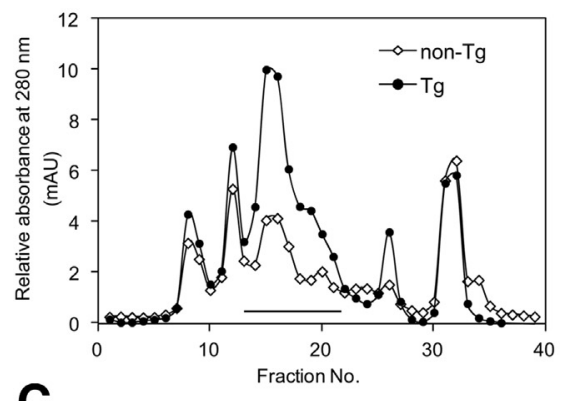

C

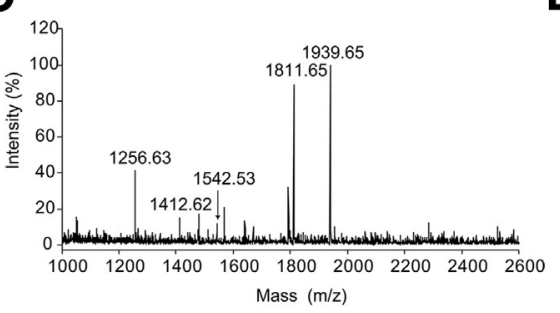

B

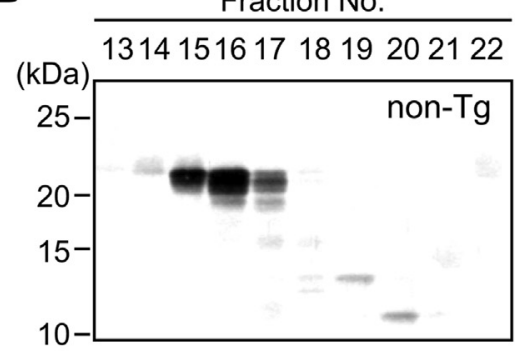

D

\begin{tabular}{|ccl|}
\hline Residues & $\begin{array}{c}\text { Measured } \\
(\mathrm{M}+\mathrm{H})^{+}\end{array}$ & \multicolumn{1}{c|}{ Sequence } \\
\hline $45-56$ & 1412.62 & (R)RALDFAVSEYNK(G) \\
$46-56$ & 1256.63 & (R)ALDFAVSEYNK(G) \\
$74-90$ & 1939.65 & (R)KQLVAGVNYFLDVEMGR(T) \\
$75-90$ & 1811.65 & (K)QLVAGVNYFLDVEMGR(T) \\
$115-127$ & 1542.53 & (K)ALCSFQYYVPWK(G) \\
\hline
\end{tabular}

Fraction No

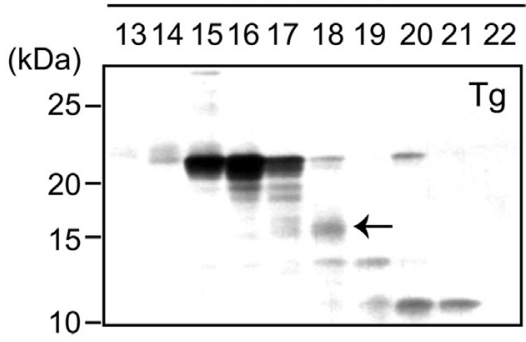

E

MASPLRSLLFLLAVLAVAWAATPKQGPRML GAPEEADANEEGVRRALDFAVSEYNKGSND AYHSRAIQVVRARKQLVAGVNYFLDVEMGR TTCTKSQTNLTDCPFHDQPHLMRKALCSFQ IYSVPWKGTHSLTKFSCKNA

Figure 1 Isolation and identification of candidate signaling molecules to regulate neuronal $\alpha$-syn accumulation. A: CM samples from primary neural cultures were fractionated by sequential ultrafiltration and mono 0 chromatography. The collected proteins were fractionated by Superdex 200 gel filtration chromatography. Protein concentrations in the CM from non- $\mathrm{Tg}$ (diamonds) and Tg (circles) mice were estimated by absorbance at $280 \mathrm{~nm}$. B: Fractions 13 to 22 were separated by SDS-PAGE, and the proteins were visualized by silver staining; $\mathrm{CM}$ were derived from non- $\mathrm{Tg}$ (left panel) and Tg mice (right panel). A 14.9-kDa band (arrow) was specifically detected in fraction 18 obtained from Tg mouse primary cells and was excised from the SDS-polyacrylamide gel for mass spectrometric analysis. C: The 14.9-kDa band was subjected to in-gel digestion with trypsin, and the extracted peptides were analyzed by MALDI-TOF MS. D: Five peptide masses $(1256.63,1412.62,1542.53,1811.65$, and 1939.65) matched mouse cystatin C. E: The tryptic peptides (bold) cover 42 of 140 amino acids of the cystatin C protein. 
(Merck, Darmstadt, Germany). To generate stable cell lines, Cst 3 cDNA was first cloned into the pDsRed-Monomer-HygroC1 vector (Takara Bio). COS-7 cells maintained in Dulbecco's modified Eagle's medium (Sigma-Aldrich) supplemented with $10 \%$ fetal bovine serum were transfected with the Cst3 vector by using FuGENE 6 (Roche Applied Science, Basel, Switzerland) according to the manufacturer's instructions. To select stable clones, transfected cells were cultured for 2 weeks in $400 \mu \mathrm{g} / \mathrm{mL}$ hygromycin B (Life Technologies), and surviving colonies were transferred to separate culture dishes and
A Primary cultured cells

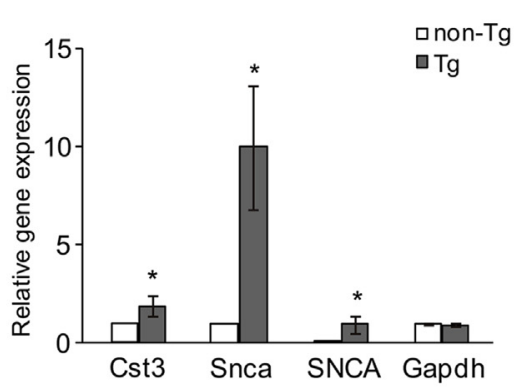

B Mouse brain

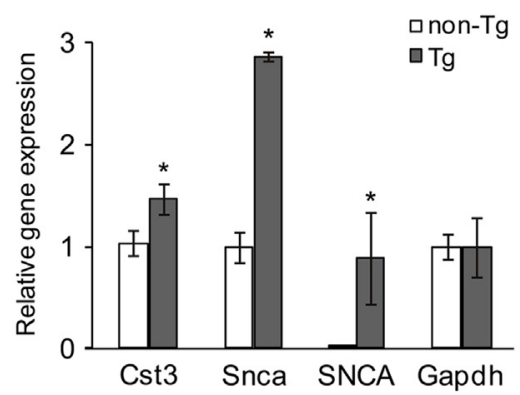

C
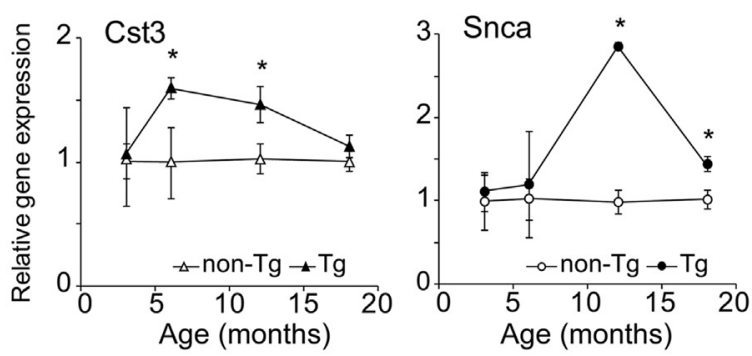

2. Gapdh

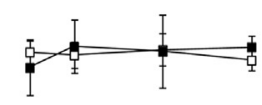

$\begin{array}{lll}5 & 10 \quad 15 & 20\end{array}$

Age (months)
D

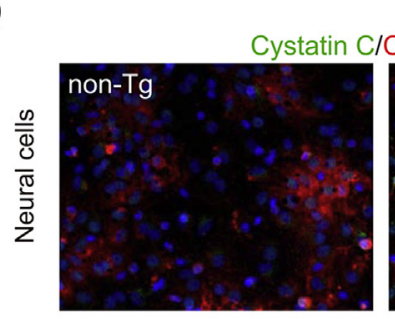

$\mathbf{F}$

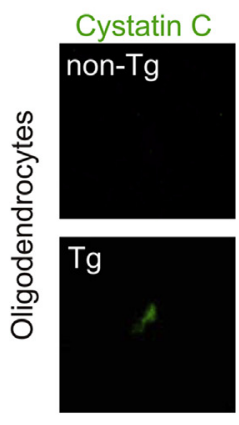

G

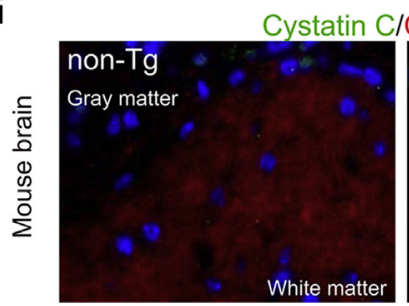

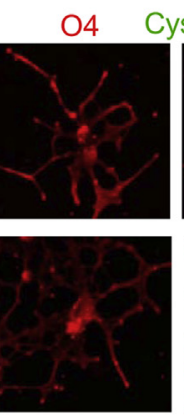
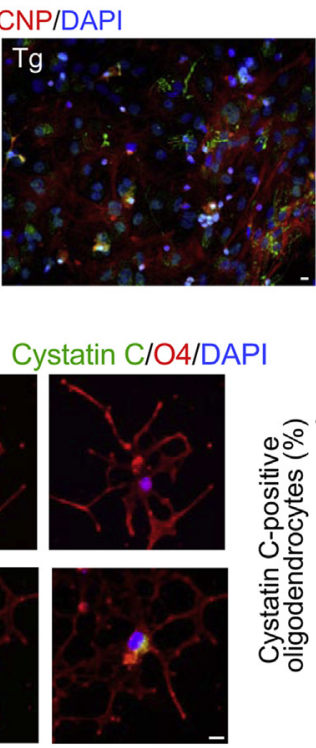

E

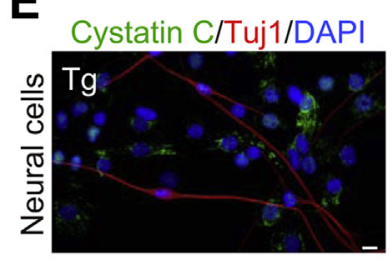

Figure 2 Up-regulation of Cst3 expression in the Tg-mouse CNS. A and B: The mRNAs of Cst3, Snca, and SNCA in cultured neuronal and glial cells at DIV36 (A) and brain tissues of $\mathrm{Tg}$ and non- $\mathrm{Tg}$ mice at 12 months of age (B) were measured by qPCR. The expression of Cst3 and Snca mRNAs in Tg mice is shown as a ratio to that in non- $\mathrm{Tg}$ mice. C: Age-dependent changes in the relative expression levels of Snca and Cst3 mRNAs were analyzed by qPCR. Gapdh mRNA was used as an internal control. Data are expressed as the means \pm SD $(n=3) .{ }^{*} P<0.05$, Student's $t$-test. D: Cultured neuronal and glial cells from $\mathrm{Tg}$ and non- $\mathrm{Tg}$ mice were fixed at DIV36 and immunostained for cystatin C (green) and oligodendrocyte marker CNP (red). Cell nuclei were counterstained with DAPI (blue). E: The cells were immunostained for cystatin C (green) and neuronal marker Tuj1 (red). Double labeling showed that cystatin $C$ was localized in the oligodendrocytic cytoplasm. Cystatin C immunoreactivity was stronger in oligodendrocytes derived from $\mathrm{Tg}$ mice than oligodendrocytes from non- $\mathrm{Tg}$ mice. F: Oligodendrocyte cultures from $\mathrm{Tg}$ and non-Tg mice were fixed at DIV25 and immunostained for cystatin C (green) and the oligodendrocyte marker (red). Cystatin C was localized in the oligodendrocytic cytoplasm. The ratio of cystatin C-positive cells in the oligodendrocytes was calculated. The mean percentage of cystatin C-positive cells from five different microscopic fields is plotted. Data are expressed as the means \pm SD. ${ }^{\star} P<0.05$, Student's $t$-tests. G: Sections of the spinal cord from $\mathrm{Tg}$ and non- $\mathrm{Tg}$ mice at the age of 12 months were stained by immunofluorescence with cystatin C (green) and CNP (red). H: The sections were also immunostained with cystatin $C$ and developed with diaminobenzidine. Cystatin C was detected in oligodendrocytes of the $\mathrm{Tg}$ mouse CNS (arrows). Scale bars: $10 \mu \mathrm{m}(\mathbf{D}-\mathbf{H})$. 
grown in $200 \mu \mathrm{g} / \mathrm{mL}$ hygromycin B medium. Expression and secretion of cystatin $\mathrm{C}$ were confirmed in each line by immunoblot analysis. To obtain secreted cystatin $\mathrm{C}$, the cultured medium from these COS-7 cells was collected and dialyzed against $20 \mathrm{mmol} / \mathrm{L}$ Tris- $\mathrm{HCl}(\mathrm{pH}$ 7.5). The protein was then further concentrated by lyophilization. After partial purification with the use of ultrafiltration, cystatin $\mathrm{C}$ was purified by Superdex 200 gel filtration chromatography.

\section{Transient Expression of $\alpha$-Syn in Neuro2a Cells}

The mouse $\alpha$-syn gene Snca was cloned into the pcDNA3.1 vector as previously described, ${ }^{15}$ and FuGENE 6 was used to introduce exogenous DNA into Neuro2a cells. ${ }^{19}$ To induce neuronal differentiation of Neuro2a cells, the medium was replaced with Dulbecco's modified Eagle's medium supplemented with $2 \%$ fetal bovine serum and 20 $\mu \mathrm{mol} / \mathrm{L}$ retinoic acid (Sigma-Aldrich). To assay the effect of cystatin $\mathrm{C}$ on differentiated Neuro2a, cells were treated with cystatin $\mathrm{C}(1 \mu \mathrm{g} / \mathrm{mL})$ for 7 days.

\section{Sequential Extraction of $\alpha$-Syn from Cultured Cells}

Cultured cells were homogenized in high-salt buffer (50 $\mathrm{mmol} / \mathrm{L}$ Tris-HCl, pH 7.5, $750 \mathrm{mmol} / \mathrm{L} \mathrm{NaCl}, 20 \mathrm{mmol} / \mathrm{L}$ $\mathrm{NaF}$, and $10 \mathrm{mmol} / \mathrm{L}$ EGTA) at $0.5 \mathrm{~mL}$ per culture flask and centrifuged at $100,000 \times g$ for 30 minutes at $4^{\circ} \mathrm{C}$. The supernatant was the high-salt-soluble fraction. The resulting pellet was suspended in $50 \mathrm{mmol} / \mathrm{L}$ Tris- $\mathrm{HCl}$ that contained $10 \%(\mathrm{w} / \mathrm{v})$ sucrose $(\mathrm{pH} 7.5)$ to remove myelin and associated lipids. The remaining pellet was dissolved in radioimmunoprecipitation assay buffer $[50 \mathrm{mmol} / \mathrm{L}$ Tris- $\mathrm{HCl}, \mathrm{pH}$ 8.0, $150 \mathrm{mmol} / \mathrm{L} \mathrm{NaCl}, 5 \mathrm{mmol} / \mathrm{L}$ EGTA, $1 \%$ (v/v) Nonidet P-40, $0.5 \%(w / v)$ sodium deoxycholate, and $0.1 \%(w / v)$ SDS] and centrifuged at $100,000 \times g$ for 30 minutes at $4^{\circ} \mathrm{C}$. The radioimmunoprecipitation assay buffer-insoluble proteins were extracted from the pellet by sonication in $70 \%$ (v/ v) formic acid (FA). Samples extracted by FA were dried and resuspended in dissociation buffer $[0.5 \mathrm{~mol} / \mathrm{L}$ Tris- $\mathrm{HCl}$, $\mathrm{pH} 8.8,1 \%$ (w/v) SDS, 5\% (v/v) 2-mercaptoethanol]. Protein concentrations were measured by the bicinchoninic acid protein assay (Thermo Fisher Scientific, Waltham, MA). Equal amounts of samples were separated by SDS-PAGE and analyzed by immunoblot analysis.

\section{Immunocytochemical and Immunohistochemical Studies}

Primary cultured cells and Neuro2a cells on glass coverslips were fixed and stained as previously described. ${ }^{15}$ The primary antibodies used were Syn4469, anti-cystatin C (Millipore), anti-cleaved caspase-3 (Asp175; Cell Signaling Technology, Beverly, MA), anti-CNP (Lab Vision, Fremont, CA), anti-O4 (Millipore), anti- $\beta$-III tubulin (Tuj1; Covance, Princeton, $\mathrm{NJ}$ ), anti-glial fibrillary acidic protein (Sigma-Aldrich), and anti-Ibal (Wako). Syn4469 is a polyclonal antibody that selectively recognizes mouse $\alpha$-syn residues 115 to $125 .^{15}$ After incubation with a primary antibody, the cells were incubated for 1 hour with a fluorophore-conjugated secondary antibody (Alexa 488- or Alexa 594-conjugated goat antimouse IgG or anti-rabbit IgG; Life Technologies). In situ labeling of fragmented genomic DNA in primary cultured cells was performed with the In Situ Cell Death Detection Kit, Fluorescein (Roche Applied Science) according to the manufacturer's instructions. TUNEL-positive cells were counted by a blinded observer and the average was calculated.

For immunohistochemistry, anesthetized mice were perfused transcardially with PBS. Mouse brains were fixed in 10\% neutral-buffered formalin and were sectioned. Sections were blocked with $2 \%$ fetal bovine serum in $0.1 \mathrm{~mol} / \mathrm{L}$ Tris- $\mathrm{HCl}(\mathrm{pH}$ 7.5) and incubated overnight at $4^{\circ} \mathrm{C}$ with primary antibodies. Sections were reacted with biotinylated-conjugated secondary antibodies and developed with diaminobenzidine by using the Vectastain ABC Kit (Vector Laboratories, Burlingame, CA), as previously described. ${ }^{20} \mathrm{~A}$ double-labeling immunofluorescence study was conducted to evaluate the colocalization of oligodendrocytes and cystatin C in the mouse CNS. Nuclei were visualized by counterstaining with DAPI.

\section{Immunoblot Analysis}

Samples were electrophoretically separated on 12\% SDSpolyacrylamide gels and transferred to polyvinylidene difluoride membranes (GE Healthcare). The polyvinylidene difluoride membranes were incubated in 5\% nonfat milk powder in Tris-buffered saline and then incubated with Syn4469 and anti-160-kDa neurofilament (NF160; SigmaAldrich), followed by incubation in a horseradish peroxidase-conjugated secondary antibody. To enhance the immunoreactions, we used the Can Get Signal Immunostain Solution (Toyobo, Osaka, Japan) to dilute primary and secondary antibodies. Immunoreactive proteins were visualized with an electrochemiluminescence plus system (GE Healthcare). Densitometric measurement of the signals was performed with ImageJ software version $1.43 \mathrm{u}(\mathrm{NIH}$, Bethesda, MD).

\section{Statistical Analysis}

Data are expressed as means \pm SD. Statistical analysis was performed by Student's $t$-test. A $P$ value of $<0.05$ was considered to be statistically significant.

\section{Results}

Identification of an Oligodendrocytic Signaling Molecule that Triggers Neuronal $\alpha$-Syn Accumulation in a Mouse Model of MSA

To identify oligodendrocytic signaling molecules that can trigger neuronal degeneration in the MSA mouse model, $\mathrm{CM}$ samples from primary cultures of $\mathrm{Tg}$ and non- $\mathrm{Tg}$ 
mouse brains were fractionated, and the molecular constituents were compared. After separation of CM by ultrafiltration and anion exchange chromatography, the flowthrough solution was fractionated with the use of size exclusion chromatography (Figure 1A). We observed a distinct peak in the elution profile that distinguished the $\mathrm{CM}$ of $\mathrm{Tg}$ mice from that of non- $\mathrm{Tg}$ mice. The protein fractions within this peak were separated by SDS-PAGE and visualized by silver staining (Figure 1B). We observed a distinct band at $14.9 \mathrm{kDa}$ in fraction 18 of $\mathrm{Tg}$ mice CM. This band was excised from the gel and digested with trypsin. The protein fragments were analyzed by MALDI-TOF MS (Figure 1C) and identified by searching the SWISS-PROT database with the MASCOT program (Figure 1, D and E). In this way, we identified the protein present in the $14.9-\mathrm{kDa}$ band as cystatin $\mathrm{C}$.
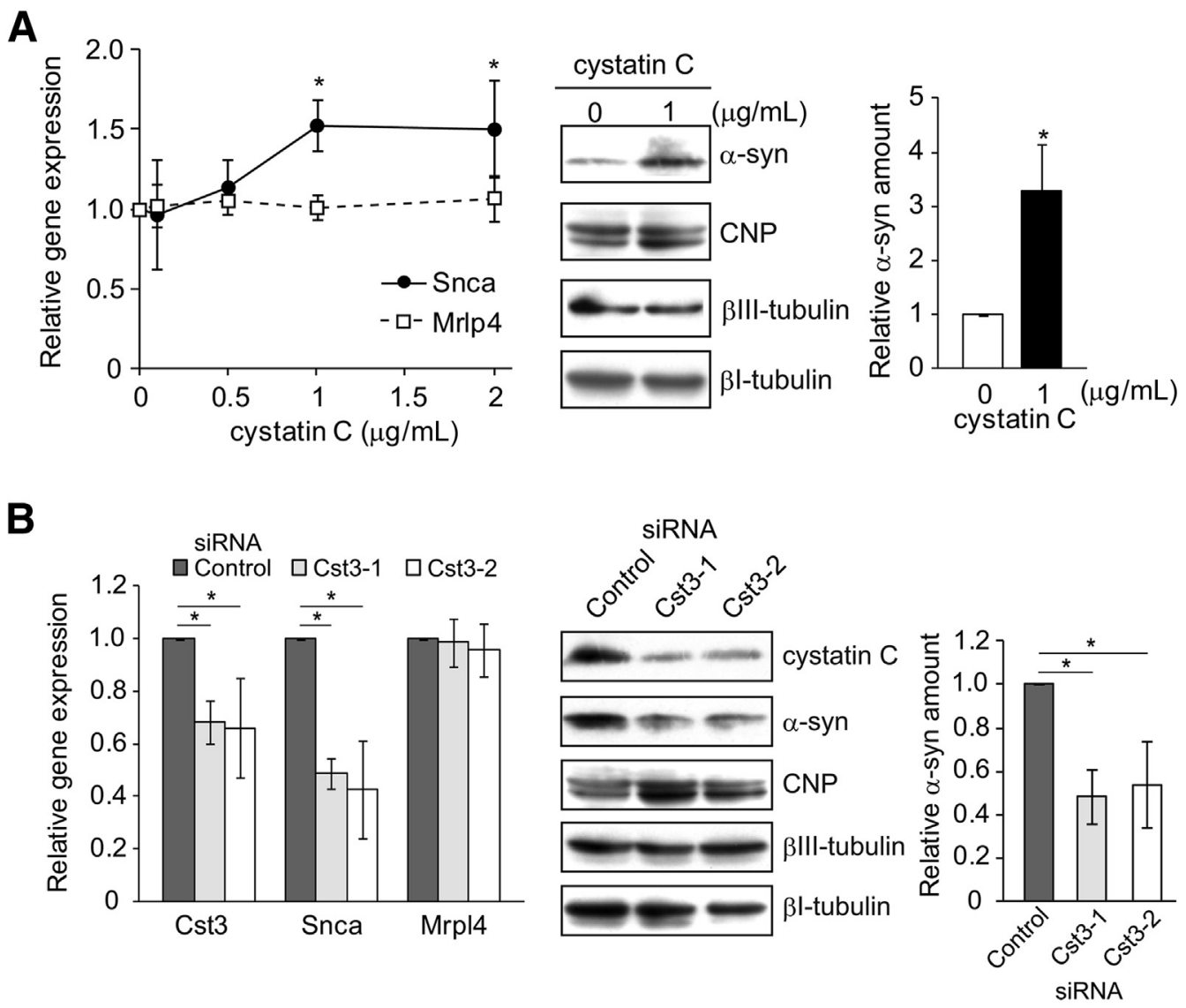

C

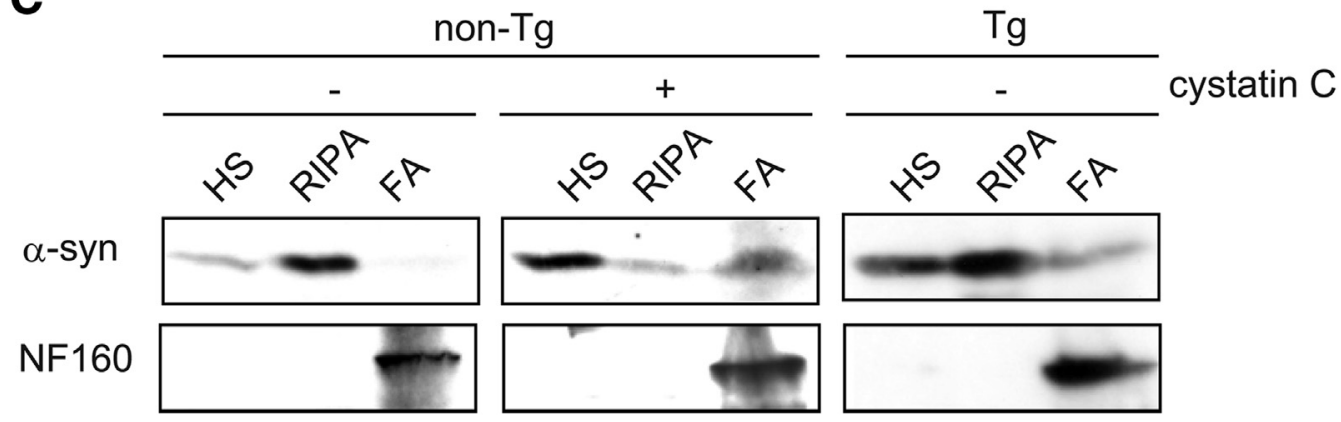

Figure 3 Accumulation of insoluble $\alpha$-syn in neurons treated with cystatin C. A: Primary cultured neural cells derived from non-Tg mice were treated with cystatin C from DIV8 to DIV36 and compared with untreated cultures. Expression of $\alpha$-syn was quantified by qPCR and immunoblot analysis. A dose-response curve of Snca mRNA expression in response to cystatin $C$ was plotted. Mrpl 4 mRNA was used as an internal control. $\alpha$-Syn signals on the immunoblots were normalized to the signals for $\beta I$-tubulin. B: Expression of cystatin $C$ was suppressed by RNA interference in primary neural cells derived from Tg mice. Two siRNA vectors (Cst3-1 and Cst3-2) or control vector were introduced into the primary neural cells. Expressions of Cst3 and Snca mRNAs were determined by qPCR, and protein depletions were assessed by immunoblots and their quantification. CNP and BIII-tubulin were used as protein markers for oligodendrocytes and neurons, respectively, in immunoblots. $\beta$ I-tubulin was used as a loading control. Data are expressed as the means \pm SD $(n=3)$. ${ }^{*} P<0.05$ by Student's $t$-tests. C: Proteins from primary cultured neural cells derived from non- $\mathrm{Tg}$ mice (control and treated with cystatin C) and Tg mice were sequentially extracted into three fractions: high-salt (HS) buffer, radioimmunoprecipitation assay (RIPA) buffer, and 70\% formic acid (FA). Neurofilament (NF160) was used as a protein marker for the neuronal insoluble protein fraction. 


\section{Elevated Cystatin C Expression by Oligodendrocytes of} the MSA Mouse Model

To determine whether $\alpha$-syn overexpression in oligodendrocytes contributes to cystatin $\mathrm{C}$ release in the Tg mouse CNS, we examined the age-dependent expression of cystatin $\mathrm{C}$ and $\alpha$-syn by quantitative real-time PCR (qPCR). Expression levels of the mouse $C s t 3$ and the endogenous Snca genes were significantly higher in $\mathrm{Tg}$ mouse neural cells than in non- $\mathrm{Tg}$ mouse neural cells (Figure 2A). Similarly, the expression of Cst3 and Snca mRNAs was up-regulated in the brain tissue of $\mathrm{Tg}$ mice at 12 months of age (Figure 2B). We then examined the expression of Cst3 and Snca mRNAs in the brains of $\mathrm{Tg}$ and non-Tg mice at 3,6,12, and 18 months of age by qPCR. Overexpression of the human $S N C A$ gene in oligodendrocytes was detected in $\mathrm{Tg}$ mouse brain at all ages from 3 months to 18 months. Inclusions that resembled GCIs were first detected at 6 months of age in the Tg CNS, ${ }^{13}$ subsequent to Cst3 mRNA expression but preceding the up-regulation of Snca mRNA expression at 12 months of age (Figure 2C).

Cystatin $\mathrm{C}$ expression has been reported in neurons, astrocytes, and microglia of several species, ${ }^{21-25}$ but it is unclear whether cystatin $\mathrm{C}$ is expressed by oligodendrocytes. Neural cells cultured from $\mathrm{Tg}$ mice exhibited stronger immunocytochemical staining for cystatin $\mathrm{C}$ than neural cells cultured from non-Tg mice, and it was selectively expressed by oligodendrocytes (Figure 2, D and E). Oligodendrocyte cultures from $\mathrm{Tg}$ mice confirmed that cystatin $\mathrm{C}$ was localized at the cytoplasm (Figure 2F). Immunohistochemical studies revealed that cystatin $\mathrm{C}$ was localized to the oligodendrocyte cytoplasm in the Tg mouse CNS (Figure 2, G and $\mathrm{H})$. These results indicate that cystatin $\mathrm{C}$ is produced by oligodendrocytes that contained $\alpha$-syn inclusions.

\section{Induction of Neuronal $\alpha$-Syn Accumulation by Cystatin C}

We previously reported that insoluble endogenous $\alpha$-syn progressively accumulated in neurons, leading to neuronal degeneration in Tg mice. ${ }^{13,15}$ To examine the up-regulation of Snca mRNA by cystatin C, primary cultured cells derived from non-Tg mice were exposed to a dose (0.1 to 2 $\mu \mathrm{g} / \mathrm{mL}$ ) of cystatin C for DIV8 to DIV36 (Figure 3A). We found that a $1-\mu \mathrm{g} / \mathrm{mL}$ concentration of cystatin $\mathrm{C}$ was sufficient to stimulate a significant increase in Snca mRNA expression. To assess the effect of cystatin $\mathrm{C}$ on protein synthesis of $\alpha$-syn, primary neural cultures from non-Tg mice were treated with $1 \mu \mathrm{g} / \mathrm{mL}$ cystatin $\mathrm{C}$ and compared with untreated neural cultures by immunoblot analysis. Both qPCR and immunoblot analysis revealed neuronal accumulation of endogenous $\alpha$-syn induced by cystatin $C$ treatment (Figure 3A). Moreover, knockdown of Cst3 in Tg mouse cells resulted in the down-regulation of Snca mRNA expression (Figure 3B). We further analyzed the biochemical properties of $\alpha$-syn in cultured neural cells treated with cystatin C. Sequential protein extraction showed that most $\alpha$-syn
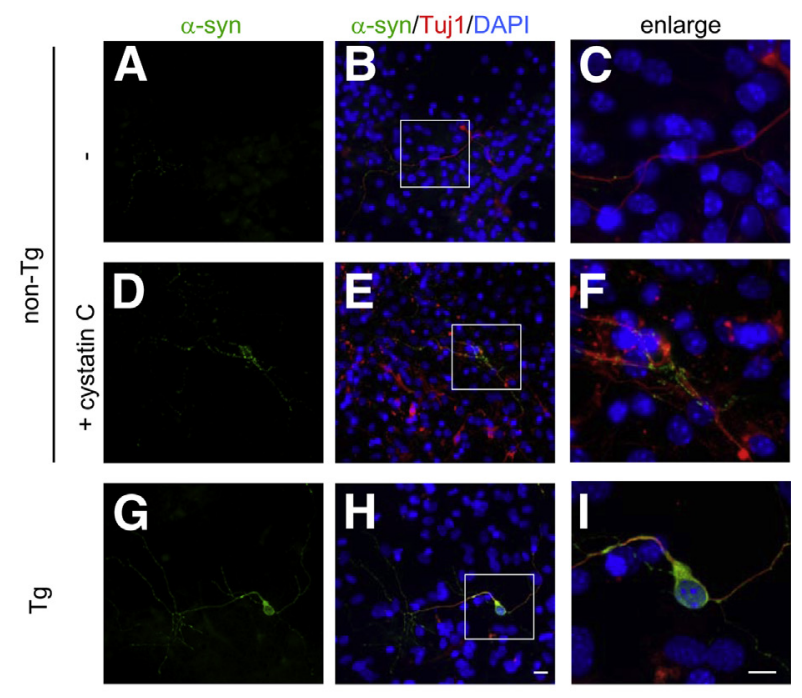

$\alpha$-syn/Tuj1/DAPI
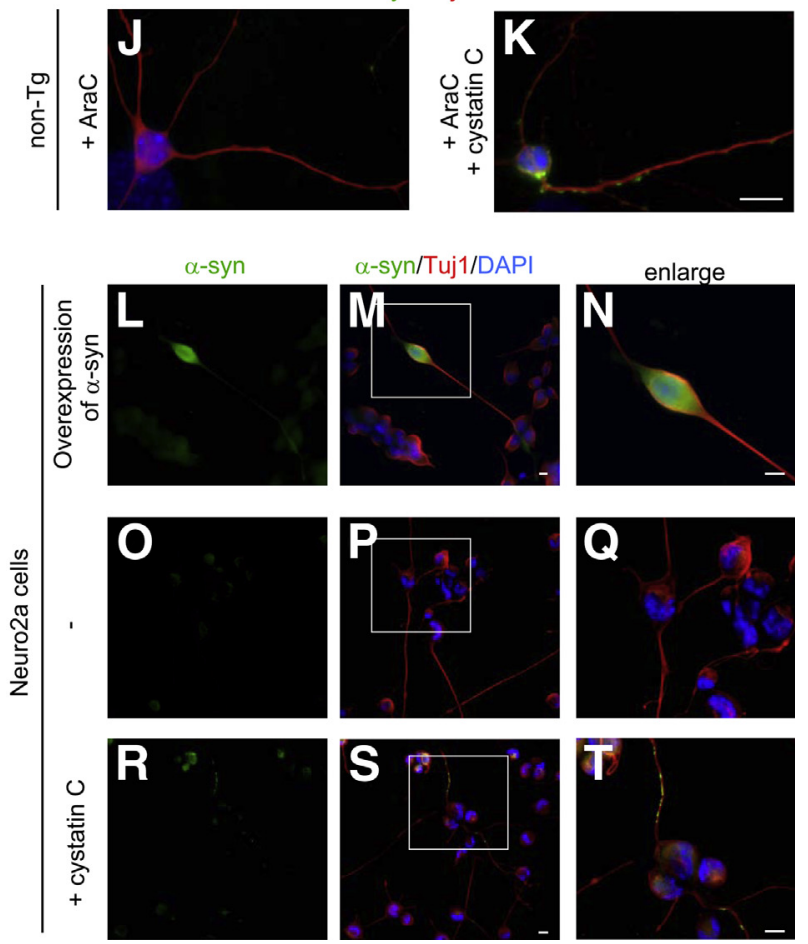

Figure 4 Effect of cystatin C on neuronal $\alpha$-syn accumulation. A-K: Primary cultured neural cells derived from non- $\mathrm{Tg}$ mice were treated with cystatin $C$ (D-F) and compared with untreated cells $(\mathbf{A}-\mathbf{C})$ and untreated Tg mouse cells $(\mathbf{G}-\mathbf{I})$. The cells were exposed to AraC to enrich neurons in the culture. Enriched neuronal cultures were treated with (K) or without (J) cystatin C. Primary neural cultures and enriched neuronal cultures were fixed and studied by immunofluorescence. Double-labeling immunocytochemistry revealed that the upregulation of $\alpha$-syn expression in response to cystatin $C$ treatment was restricted to neurons, particularly axons. L-T: Neuro2a cells overexpressing mouse $\alpha$-syn were followed by differentiation $(\mathbf{L}-\mathbf{N})$, and Neuroza cells treated with cystatin $\mathbf{C}$ for 7 days $(\mathbf{R}-\mathbf{T})$ and untreated $(\mathbf{0}-\mathbf{Q})$ after differentiation. When $\alpha$-syn was overexpressed by transfection, $\alpha$-syn protein was diffusely distributed throughout the cytoplasm and neurites, consistent with a soluble protein. In contrast, $\alpha$-syn expressed after cystatin $C$ treatment formed clusters in the neurites. Cells were stained with anti-mouse $\alpha$-syn antibody (green) and an antibody against the neuron-specific $\beta$-III tubulin, Tuj1 (red). The area highlighted by the white box is enlarged in the right panels. Nuclei were counterstained with DAPI (blue). Scale bars: $10 \mu \mathrm{m}$ (H, I, K, M, N, S, and T). 
A

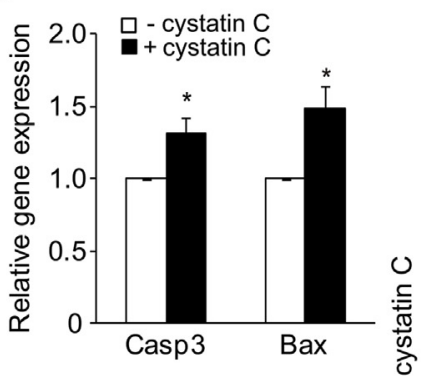

cystatin C

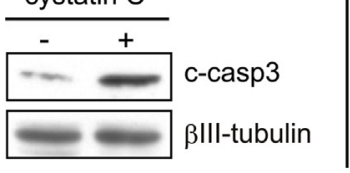

B
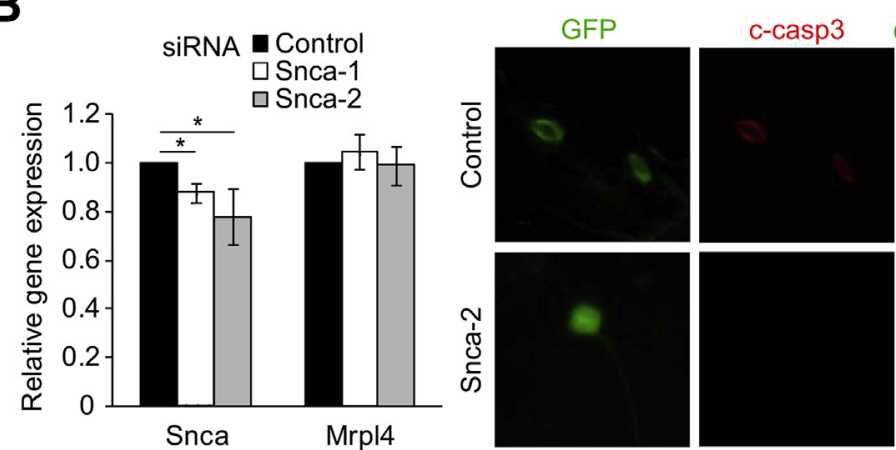

C

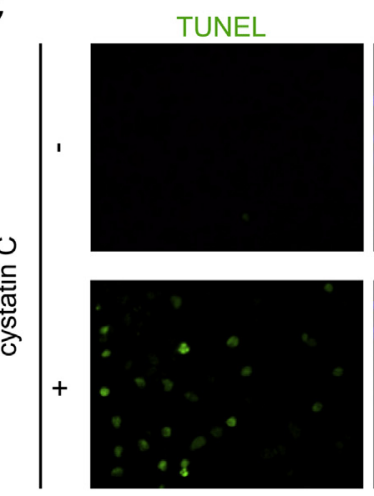

TUNEL/Tuj1/DAPI
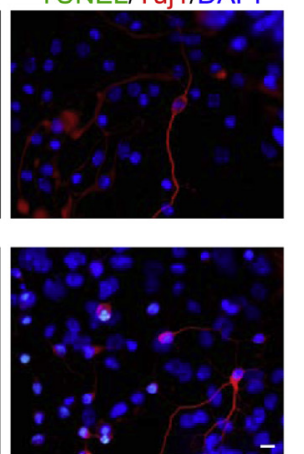

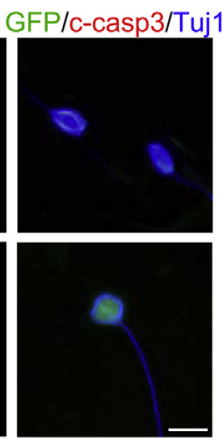

c-casp3/Tuj1/DAPI
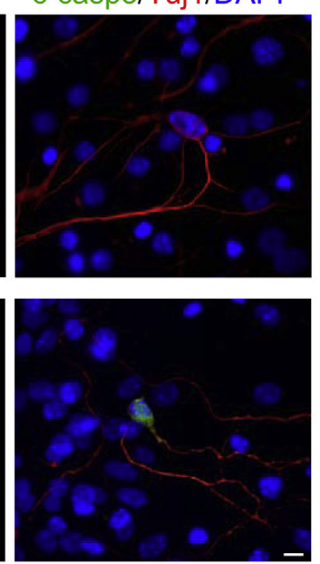

D

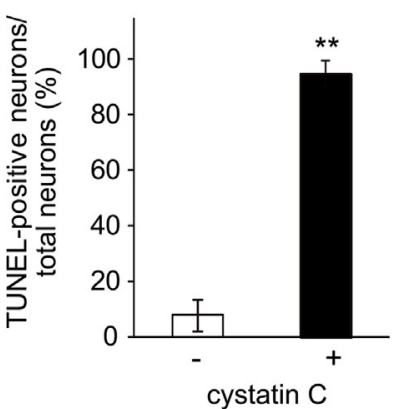

Figure 5 Apoptotic neuronal degeneration induced by cystatin C. Primary neural cells derived from non-Tg mice were treated with cystatin $C$ from DIV8 to DIV36. A: Elevated expression levels of Bax and Casp3 mRNAs in the cultured cells were quantified by qPCR. Cystatin $C$ treatment increased the immunoreactivity of the cleaved caspase- 3 on immunoblots stained by the antibody against cleaved caspase-3 (c-casp3). Double-labeling immunofluorescence showed that neurons (red) were selectively stained by the c-casp3 antibody (green). B: Two siRNA vectors (Snca-1 and Snca-2) or control vector with GFP were introduced into the primary neural cells, and expression of Snca mRNA was determined by $\mathrm{qPCR}$ and quantified. The ccasp3 was examined by immunofluorescence to assess neurotoxicity in the primary neurons by using the antibody against c-casp3 (red) and Tuj1 (blue). C: TUNEL staining to detect apoptotic cells (green) was performed on non-Tg primary cells treated with cystatin C. Neurons were identified by double-labeling with Tuj1. The cells undergoing apoptotic cell death were primarily neurons. D: The ratio of TUNEL-positive neurons in all neurons was calculated. The mean percentage of TUNEL-positive nuclei from 10 different microscopic fields is plotted. Data are expressed as the means \pm SD. ${ }^{*} P<0.05,{ }^{* *} P<0.01$, Student's $t$-tests. Scale bars: $10 \mu \mathrm{m}(\mathbf{A}-\mathbf{C})$. GFP, green fluorescent protein. accumulation in Tg neurons was in the insoluble FA fraction, whereas cystatin $\mathrm{C}$ treatment enhanced insoluble $\alpha$-syn accumulation in the FA fraction extracted from non-Tg neurons (Figure 3C).

To determine the intracellular localization of insoluble $\alpha$ syn accumulation, primary neural cultures (Figure 4, A-I) and AraC-treated neuronal cultures (Figure 4, J and K) from non-Tg mice treated with cystatin $\mathrm{C}$ as described were immunocytochemically stained with an anti-synuclein antibody. Staining revealed accumulation of $\alpha$-syn puncta in the soma and axons of these cystatin C-treated non-Tg neurons. This subcellular distribution was in marked contrast to the diffuse staining observed in the differentiated neuroblastoma line (Neuro2a) after transfection with mouse $\alpha$-syn, a staining pattern consistent with soluble $\alpha$-syn expression (Figure 4, L-N). However, when untransfected Neuro2a cells were treated with cystatin $\mathrm{C}, \boldsymbol{\alpha}$-syn staining appeared in clusters (Figure 4, O-T). The distinct staining patterns of Snca-transfected Neuro2a cells and cystatin C-treated Neuro2a cells indicated that cystatin $C$ not only triggers the up-regulation of $\alpha$-syn expression in neurons but also contributes to the accumulation of insoluble $\alpha$-syn.

\section{Neuronal Degeneration Induced by Cystatin C}

To investigate whether cystatin $\mathrm{C}$ can induce neurodegeneration by enhancing insoluble $\alpha$-syn accumulation, we compared the expression of apoptotic markers and 
genomic DNA fragmentation between cystatin C-treated non- $\mathrm{Tg}$ neural cultures and control non-Tg neural cultures. qPCR revealed up-regulation of the Bax gene, a member of the Bcl-2 family that accelerates apoptosis, and the apoptosis effector gene Casp3 in response to cystatin $\mathrm{C}$ treatment (Figure 5A). Immunofluorescence studies and immunoblot analysis showed that cystatin $\mathrm{C}$ activated caspase- 3 in primary neurons (Figure 5A). When $\alpha$-syn was down-regulated by RNA interference in the cystatin C-treated neurons, the cleaved caspase-3 was decreased (Figure 5B). TUNEL staining showed that cystatin $\mathrm{C}$ increased apoptosis (Figure 5, $\mathrm{C}$ and $\mathrm{D}$ ). These results indicate that cystatin $\mathrm{C}$ is an oligodendrocytic signaling molecule that can induce neuronal degeneration in the mouse CNS.

\section{Discussion}

The interaction between oligodendrocytes and neurons plays a key role in the MSA neurodegeneration. Our study indicates that oligodendrocytes overexpressing human $\alpha$-syn release signals that up-regulate neuronal expression of $\alpha$-syn in an animal model of MSA. We identified cystatin $\mathrm{C}$ as one of these signals and demonstrated that this oligodendroglial protein triggered the accumulation of insoluble $\alpha$-syn in neurons. We propose that cystatin $\mathrm{C}$ released by oligodendrocytes containing $\alpha$-syn inclusions triggers neuronal degeneration in MSA.

Many neurodegenerative diseases are associated with the accumulation of specific proteins in the CNS, but the events that initiate this accumulation remain unclear. Intracellular transmission of exogenous protein aggregates is well documented in prion disorders. ${ }^{26}$ In other neurodegenerative diseases associated with misfolded proteins such as $\beta$-amyloid (A $\beta)$, tau, and $\alpha$-syn, it has also been proposed that aggregates of misfolded proteins propagate the misfolded state in a prion-like manner. ${ }^{27-33}$ Growing evidence suggests that cell-cell interactions contribute to the spread of neurodegeneration, but the nature of the signals is still unclear. In this study, we show that the interaction between oligodendrocytes and neurons plays an essential role in the progressive neurodegeneration associated with MSA. In the mouse model of MSA, we clearly distinguished oligodendrocytic (exogenous) $\alpha$-syn from neuronal (endogenous) $\alpha$-syn. The exogenous $\alpha$-syn in oligodendrocytes was of human origin, and the endogenous $\alpha$-syn in neurons was of mouse origin in the mouse CNS. ${ }^{13,15}$ Thus, we speculate that oligodendrocyte-derived signals may serve as a bridge between oligodendrocytic inclusions and neurodegeneration in MSA. In another MSA mouse model, expression of glial-derived neurotrophic factor was reduced, whereas infusion of glial-derived neurotrophic factor ameliorated the behavioral and neuropathological deficits but had no effect on $\alpha$-syn expression levels. ${ }^{34}$ Because the accumulation of insoluble $\alpha$-syn compromises neuronal function and viability, oligodendrocytes may release a multitude of signals with either trophic or deleterious effects on neurons. Our previous studies of the mouse model of MSA indicated that an oligodendrocyte-derived signal must up-regulate $\alpha$-syn in neurons, resulting in the accumulation of insoluble $\alpha$-syn. ${ }^{15}$ Here, we identified cystatin $\mathrm{C}$ as one oligodendrocyte-derived signaling molecule that causes neuronal accumulation of $\alpha$-syn in mouse CNS. We further need to clarify how cystatin $\mathrm{C}$ causes the neurotoxicity.

Cystatin $\mathrm{C}$ is a potent endogenous inhibitor of cysteine protease. It is also a secretory protein found in mammalian body fluids, including cerebrospinal fluid and tissues, ${ }^{35}$ and is highly abundant in brain tissue. ${ }^{36} \mathrm{~A}$ variant of cystatin $\mathrm{C}$ is the major constituent of amyloid deposited in the brains of patients with hereditary cerebral hemorrhage with amyloidosis, Icelandic type, ${ }^{37}$ also called hereditary cystatin $\mathrm{C}$ amyloid angiopathy ${ }^{38}$ Overexpression of human cystatin $\mathrm{C}$ in the brains of Tg mice overexpressing the $A \beta$ precursor protein reduces cerebral $A \beta$ deposition, because cystatin $C$ binds $A \beta$ and inhibits its fibril formation. ${ }^{39,40}$ Conversely, cystatin $\mathrm{C}$ also regulates soluble $A \beta$ and $A \beta$-associated neuronal defects by inhibiting cathepsin $\mathrm{B}$-induced $\mathrm{A} \beta$ degradation in vivo. ${ }^{41}$ Thus, functional roles of cystatin $\mathrm{C}$ for amyloidosis are controversial.

The present study shows that cystatin $\mathrm{C}$ mediates the interaction between oligodendrocytes and neurons and is crucial for pathogenesis in the MSA mouse model. Cst 3 expression preceded the up-regulation of endogenous Snca expression, and the increase in endogenous Snca expression and intraneuronal $\alpha$-syn accumulation corresponded to the onset of motor impairments in $\mathrm{Tg}$ mice. ${ }^{13}$ Moreover, the consistent delay between the oligodendrocytic $C s t 3$ up-regulation and neuronal Snca up-regulation suggests that accumulation of endogenous $\alpha$-syn in neurons depends on oligodendrocytic Cst3 upregulation induced by GCI formation.

In conclusion, we demonstrated that oligodendrocytic cystatin $\mathrm{C}$ release induced by the formation of GCIs causes neuronal $\alpha$-syn up-regulation and accumulation and may contribute to neuronal degeneration in a mouse model of MSA. Because cystatin $\mathrm{C}$ is an extracellular protein, it may have a unique potential for a novel therapeutic target for MSA.

\section{Acknowledgments}

We thank Dr. Virginia Lee for providing MSA Tg mice.

Y.S. and I.Y. designed the experiments. Y.S. performed experiments. C.J. and I.Y. performed immunohistochemical experiments.

\section{References}

1. Lee Y, Morrison BM, Li Y, Lengacher S, Farah MH, Hoffman PN, Liu Y, Tsingalia A, Jin L, Zhang PW, Pellerin L, Magistretti PJ, Rothstein JD: Oligodendroglia metabolically support axons and contribute to neurodegeneration. Nature 2012, 487:443-448

2. Graham JG, Oppenheimer DR: Orthostatic hypotension and nicotine sensitivity in a case of multiple system atrophy. J Neurol Neurosurg Psychiatry 1969, 32:28-34

3. Gilman S, Wenning GK, Low PA, Brooks DJ, Mathias CJ, Trojanowski JQ, Wood NW, Colosimo C, Dürr A, Fowler CJ, Kaufmann H, Klockgether T, Lees A, Poewe W, Quinn N, Revesz T, Robertson D, Sandroni P, Seppi K, Vidailhet M: Second consensus 
statement on the diagnosis of multiple system atrophy. Neurology 2008, 71:670-676

4. Wenning GK, Stefanova N: Recent developments in multiple system atrophy. J Neurol 2009, 256:1791-1808

5. Papp MI, Kahn JE, Lantos PL: Glial cytoplasmic inclusions in the CNS of patients with multiple system atrophy (striatonigral degeneration, olivopontocerebellar atrophy and Shy-Drager syndrome). J Neurol Sci 1989, 94:79-100

6. Arima K, Uéda K, Sunohara N, Arakawa K, Hirai S, Nakamura M, Tonozuka-Uehara H, Kawai M: NACP/ $\alpha$-synuclein immunoreactivity in fibrillary components of neuronal and oligodendroglial cytoplasmic inclusions in the pontine nuclei in multiple system atrophy. Acta Neuropathol 1998, 96:439-444

7. Tu PH, Galvin JE, Baba M, Giasson B, Tomita T, Leight S, Nakajo S, Iwatsubo T, Trojanowski JQ, Lee VM: Glial cytoplasmic inclusions in white matter oligodendrocytes of multiple system atrophy brains contain insoluble $\alpha$-synuclein. Ann Neurol 1998, 44:415-422

8. Spillantini MG, Crowther RA, Jakes R, Cairns NJ, Lantos PL, Goedert M: Filamentous $\alpha$-synuclein inclusions link multiple system atrophy with Parkinson's disease and dementia with Lewy bodies. Neurosci Lett 1998, 251:205-208

9. Spillantini MG, Goedert M: The $\alpha$-synucleinopathies: Parkinson's disease, dementia with Lewy bodies, and multiple system atrophy. Ann N Y Acad Sci 2000, 920:16-27

10. Goedert M: Alpha-synuclein and neurodegenerative diseases. Nat Rev Neurosci 2001, 2:492-501

11. Kahle PJ, Neumann M, Ozmen L, Muller V, Jacobsen H, Spooren W, Fuss B, Mallon B, Macklin WB, Fujiwara H, Hasegawa M, Iwatsubo T, Kretzschmar HA, Haass C: Hyperphosphorylation and insolubility of $\alpha$-synuclein in transgenic mouse oligodendrocytes. EMBO Rep 2002, 3:583-588

12. Shults CW, Rockenstein E, Crews L, Adame A, Mante M, Larrea G, Hashimoto M, Song D, Iwatsubo T, Tsuboi K, Masliah E: Neurological and neurodegenerative alterations in a transgenic mouse model expressing human $\alpha$-synuclein under oligodendrocyte promoter: implications for multiple system atrophy. J Neurosci 2005, 25:10689-10699

13. Yazawa I, Giasson BI, Sasaki R, Zhang B, Joyce S, Uryu K, Trojanowski JQ, Lee VM: Mouse model of multiple system atrophy: $\alpha$-synuclein expression in oligodendrocytes causes glial and neuronal degeneration. Neuron 2005, 45:847-859

14. Ito H, Nakayama K, Jin C, Suzuki Y, Yazawa I: $\alpha$-Synuclein accumulation reduces GABAergic inhibitory transmission in a model of multiple system atrophy. Biochem Biophys Res Commun 2012, 428:348-353

15. Nakayama K, Suzuki Y, Yazawa I: Microtubule depolymerization suppresses $\alpha$-synuclein accumulation in a mouse model of multiple system atrophy. Am J Pathol 2009, 174:1471-1480

16. Nakayama K, Suzuki Y, Yazawa I: Binding of neuronal $\alpha$-synuclein to $\beta$-III tubulin and accumulation in a model of multiple system atrophy. Biochem Biophys Res Commun 2012, 417:1170-1175

17. McCarthy KD, de Vellis J: Preparation of separate astroglial and oligodendroglial cell cultures from rat cerebral tissue. J Cell Biol 1980, 85:890-902

18. Vandesompele J, De Preter K, Pattyn F, Poppe B, Van Roy N, De Paepe A, Speleman F: Accurate normalization of real-time quantitative RT-PCR data by geometric averaging of multiple internal control genes. Genome Biol 2002, 3. RESEARCH0034

19. Suzuki Y, Nakayama K, Hashimoto N, Yazawa I: Proteolytic processing regulates pathological accumulation in dentatorubralpallidoluysian atrophy. FEBS J 2010, 277:4873-4887

20. Yazawa I, Nakase H, Kurisaki H: Abnormal dentatorubral-pallidoluysian atrophy (DRPLA) protein complex is pathologically ubiquitinated in DRPLA brains. Biochem Biophys Res Commun 1999, 260:133-138

21. Yasuhara O, Hanai K, Ohkubo I, Sasaki M, McGeer PL, Kimura H: Expression of cystatin $\mathrm{C}$ in rat, monkey and human brains. Brain Res 1993, 628:85-92

22. Palm DE, Knuckey NW, Primiano MJ, Spangenberger AG, Johanson CE: Cystatin C, a protease inhibitor, in degenerating rat hippocampal neurons following transient forebrain ischemia. Brain Res 1995, 691:1-8
23. Nishio C, Yoshida K, Nishiyama K, Hatanaka H, Yamada M: Involvement of cystatin $\mathrm{C}$ in oxidative stress-induced apoptosis of cultured rat CNS neurons. Brain Res 2000, 873:252-262

24. Xu L, Sheng J, Tang Z, Wu X, Yu Y, Guo H, Shen Y, Zhou C, Paraoan L, Zhou J: Cystatin C prevents degeneration of rat nigral dopaminergic neurons: in vitro and in vivo studies. Neurobiol Dis 2005, 18:152-165

25. Pirttilä TJ, Lukasiuk K, Håkansson K, Grubb A, Abrahamson M, Pitkänen A: Cystatin C modulates neurodegeneration and neurogenesis following status epilepticus in mouse. Neurobiol Dis 2005, 20:241-253

26. Caughey B: Transmissible spongiform encephalopathies, amyloidoses and yeast prions: common threads? Nat Med 2000, 6:751-754

27. Kane MD, Lipinski WJ, Callahan MJ, Bian F, Durham RA, Schwarz RD, Roher AE, Walker LC: Evidence for seeding of $\beta$-amyloid by intracerebral infusion of Alzheimer brain extracts in $\beta$-amyloid precursor protein-transgenic mice. J Neurosci 2000, 20:3606-3611

28. Meyer-Luehmann M, Coomaraswamy J, Bolmont T, Kaeser S, Schaefer C, Kilger E, Neuenschwander A, Abramowski D, Frey P, Jaton AL, Vigouret JM, Paganetti P, Walsh DM, Mathews PM, Ghiso J, Staufenbiel M, Walker LC, Jucker M: Exogenous induction of cerebral $\beta$-amyloidogenesis is governed by agent and host. Science 2006, 313:1781-1784

29. Clavaguera F, Bolmont T, Crowther RA, Abramowski D, Frank S, Probst A, Fraser G, Stalder AK, Beibel M, Staufenbiel M, Jucker M, Goedert M, Tolnay M: Transmission and spreading of tauopathy in transgenic mouse brain. Nat Cell Biol 2009, 11:909-913

30. de Calignon A, Polydoro M, Suárez-Calvet M, William C, Adamowicz DH, Kopeikina KJ, Pitstick R, Sahara N, Ashe KH, Carlson GA, Spires-Jones TL, Hyman BT: Propagation of tau pathology in a model of early Alzheimer's disease. Neuron 2012, 73:685-697

31. Desplats P, Lee HJ, Bae EJ, Patrick C, Rockenstein E, Crews L, Spencer B, Masliah E, Lee SJ: Inclusion formation and neuronal cell death through neuron-to-neuron transmission of $\alpha$-synuclein. Proc Natl Acad Sci U S A 2009, 106:13010-13015

32. Luk KC, Song C, O'Brien P, Stieber A, Branch JR, Brunden KR, Trojanowski JQ, Lee VM: Exogenous $\alpha$-synuclein fibrils seed the formation of Lewy body-like intracellular inclusions in cultured cells. Proc Natl Acad Sci U S A 2009, 106:20051-20056

33. Luk KC, Kehm V, Carroll J, Zhang B, O'Brien P, Trojanowski JQ, Lee VM: Pathological $\alpha$-synuclein transmission initiates Parkinson-like neurodegeneration in nontransgenic mice. Science 2012, 338:949-953

34. Ubhi K, Rockenstein E, Mante M, Inglis C, Adame A, Patrick C, Whitney K, Masliah E: Neurodegeneration in a transgenic mouse model of multiple system atrophy is associated with altered expression of oligodendroglial-derived neurotrophic factors. J Neurosci 2010, 30: 6236-6246

35. Bobek LA, Levine MJ: Cystatins-inhibitors of cysteine proteinases. Crit Rev Oral Biol Med 1992, 3:307-332

36. Håkansson K, Huh C, Grubb A, Karlsson S, Abrahamson M: Mouse and rat cystatin $\mathrm{C}$ : Escherichia coli production, characterization and tissue distribution. Comp Biochem Physiol B Biochem Mol Biol 1996, 114:303-311

37. Gudmundsson G, Hallgrímsson J, Jónasson TA, Bjarnason O: Hereditary cerebral hemorrhage with amyloidosis. Brain 1972, 95:387-404

38. Olafsson I, Thorsteinsson L, Jensson O: The molecular pathology of hereditary cystatin C amyloid angiopathy causing brain hemorrhage. Brain Pathol 1996, 6:121-126

39. Kaeser SA, Herzig MC, Coomaraswamy J, Kilger E, Selenica ML, Winkler DT, Staufenbiel M, Levy E, Grubb A, Jucker M: Cystatin C modulates cerebral $\beta$-amyloidosis. Nat Genet 2007, 39:1437-1439

40. Mi W, Pawlik M, Sastre M, Jung SS, Radvinsky DS, Klein AM, Sommer J, Schmidt SD, Nixon RA, Mathews PM, Levy E: Cystatin C inhibits amyloid- $\beta$ deposition in Alzheimer's disease mouse models. Nat Genet 2007, 39:1440-1442

41. Sun B, Zhou Y, Halabisky B, Lo I, Cho SH, Mueller-Steiner S, Devidze N, Wang X, Grubb A, Gan L: Cystatin C-cathepsin B axis regulates amyloid beta levels and associated neuronal deficits in an animal model of Alzheimer's disease. Neuron 2008, 60:247-257 